\title{
Epidemiology of Neurocysticercosis in Mexico: From a Public Health Problem to Its Control
}

\section{Ana Flisser}

Additional information is available at the end of the chapter

http://dx.doi.org/10.5772/53839

\section{Introduction}

Cysticercosis is a parasitic disease of humans caused by the establishment of the larval stage of the cestode Taenia solium in several organs (Figure 1).
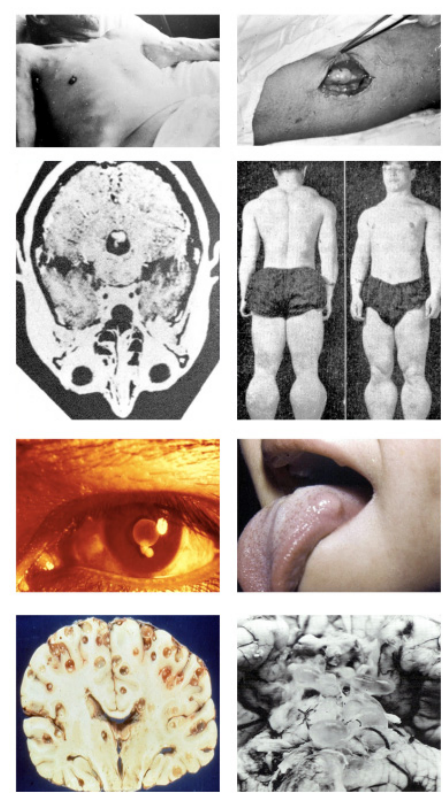

Figure 1. Images of cysticerci lodged in different locations. From top (left) to the bottom (right): diseminated sbcutaneous cysticercosis, confirmed by biopsy, lingual cysticercosis, intramuscular (pseudohypertrophy), intraocular (anterior chamber), intraventricular (IV ventricle), multiple locations of cellulosae type and subarachnoid (racemose) neurocysticercosis. 
The main clinical presentation is neurocysticercosis (NCC); it is due to the establishment of cysticerci in the Central Nervous System, where, depending on the specific location, can cause different symptoms, the main being epilepsy and hydrocephalus. Cysticercosis is a disease associated to poverty, lack of health education, inadequate hygienic habits and insufficient sanitary infrastructure; therefore it is common in underdeveloped countries. The life cycle of the parasite includes the human being, which is the only definitive host and, thus, lodges the adult tapeworm, which measures 1-4 meters long and is formed by a scolex, a neck and a long chain of proglottids that, as they are farther away from the neck, they develop into sexual maturity and, afterwards, gravidity.

Each gravid proglottid contains around 60,000 microscopic eggs; these segments are periodically released with feces. When outdoor defecation or improper latrines are found, pigs ingest feces; if contaminated with tapeworm eggs or proglottids, the embryos transform into the larval stage or cysticercus in the musculature and the central nervous system.

If humans eat insufficiently cooked or raw pork that is contaminated with cysticerci, the scolex evaginates, and with its doble row of hooks and four suckers in the rostellum, anchors to the intestinal mucosa and, after a few months, a new gravid tapeworm initiates the life cycle (Figure 2) [1].

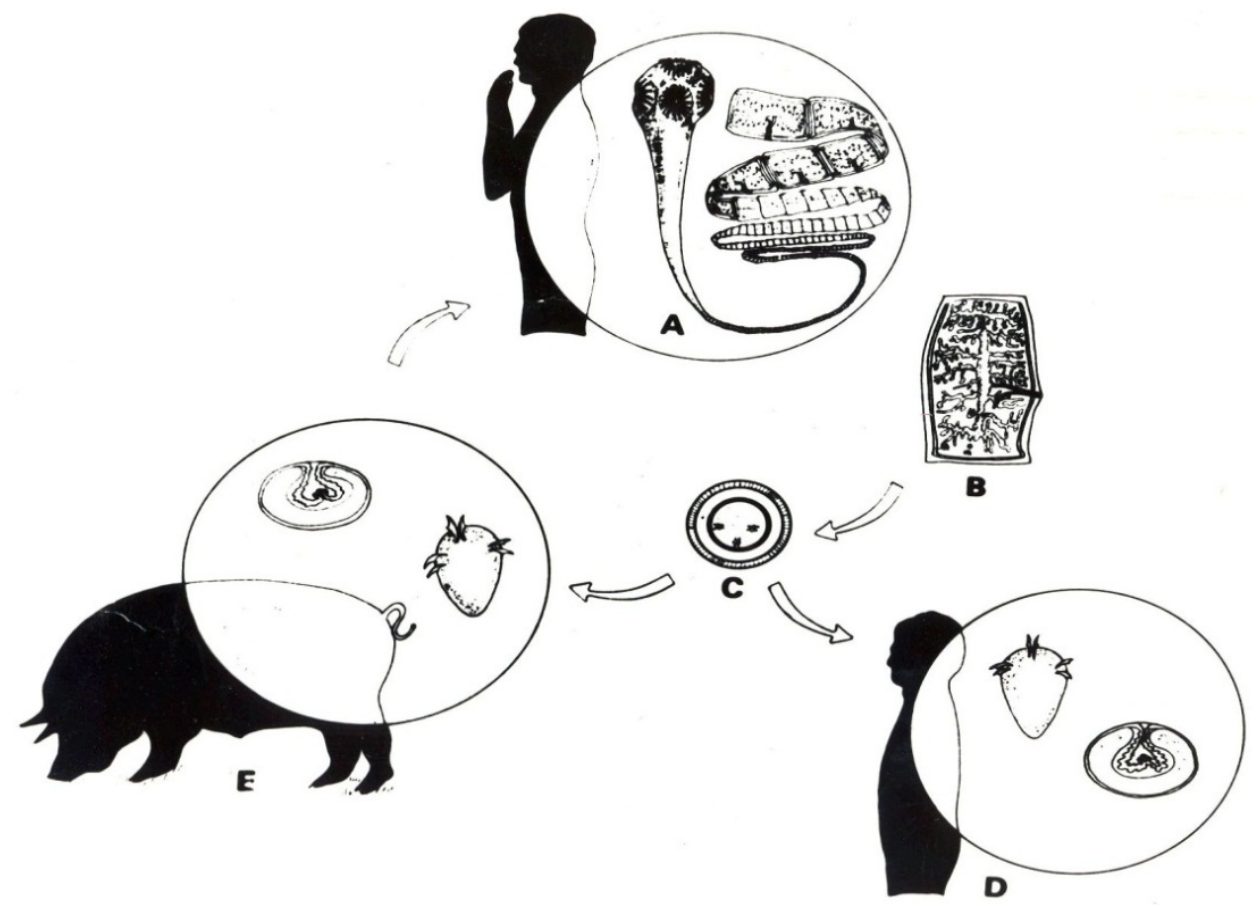

Figure 2. Life cycle of T solium. A- Adult in the small intestine. B- gravid proglotid. C- infective egg containing an oncosphere. D- Human cysticercosis. E- Porcine cysticercosis an hexacanth oncosphere and an invaginated cysticercus are drawn. 
Cysticercosis has been known since ancient times; it was detected in an Egyptian mummy by paleoparasitologists [2]. In a popular Greek theater play "The Knights" by Aristophanes, the slave Demosthenes says "We will set his mouth open with a wooden stick as the cooks do with pigs; we will tear out his tongue, and, looking down his gaping throat, will see whether his inside has any pimples" [3]. Egyptian and Greek cultures also distinguished tapeworms, but the relation between both developmental stages was not known. Probably Egiptians had Taenia saginata because they did not eat pork meat; Hipocrates, Aristoteles y Teofrastus called the worms "flatworms" while the Romans, Celsus, Galenus and Pliny the elder, called them "lumbricus latus" that meant "wideworm". At the beggining of the Christian era, some Arab authors such as Serapio, considered that each proglottid was a different worm and were named "cucurbitinum" not only because of their resemblance to pumpkin seeds, but also because these seeds were used to release tapeworms, and, interestingly, are still in use nowadays [4].

The species T. solium was described by Villanovani in 1585 and reflects the common finding of a solitary tapeworm, T. solium was differentiated from T. saginata and Diphyllobothrium latum by Tyson in 1683 who discovered and described the different types of heads or scolices of tapeworms; Redi published the following year illustrations of the scolex of dog and cat tapeworms. Van Beneden 170 years later stated that a tapeworm was animal formed by multiple individuals and that cysticerci in pigs develop after ingesting T. solium segments. At that time Kuchenmeister, in spte of severe ethical criticisms, identified that humans are the hosts of the adult stage of T. solium. In two occasions (1854 and 1859) he fed death convicts with 63 and 40 cysticerci each, and found developing tapeworms in the small intestine after necropsy. Interestingly the number of tapeworms found was 10 and 20 respectively and, since the second prisoner ingested the bladder worms much before death than the first convict (four months vs 4 days) 11 worms had mature proglottids and the largest reached five feet (1.5 meters) in length. This finding further demonstrates that $T$. solium is not necessarily a solitary parasite. He stated that the sheer number of tapeworms produced ought to convince even the most skeptical that they were derived from the cysticerci that the convicts ingested. Nevertheless he recommended that the experiment of bladder worm feeding should be allowed to be repetead on criminals under death sentences and, in the case of subsequent pardon, the tapeworms could be easily expelled, calming anxious souls and serving science at the same time [4]. Figure 3 shows pictures of some of the scientists that made outstanding contributions to the understanding of the life cycle of $\mathrm{T}$. solium: Malpighi, Tyson, van Beneden and Kuchenmeister. Not until last century the precise knowledge of the complete anatomy of a tapeworm, as well as its organization and individuality were defined, considering it a single animal.

Rumler was the first clinician that described a case of human cysticercosis in 1558 but considered it to be a tumor in the dura matter of a person with epilepsy. Panarolus, one hundred years later, reported similar cysts in the corpus callosum of the brain of an epileptic priest and Wharton found many cysticerci, that he considered to be glands in the adipose and muscle tissues of a soldier. The disease was not clearly identified as parasitic until 
Malpighi in 1698 discovered the animal nature of these cysts and described their scolex. Goeze, not knowing this study, examined swine cysticerci and described their helminthic nature. The taxonomic clasification of "Cysticercus cellulosae" was given by Zeder and Rudoplphi [4]. The use of a scientific name for this parasite was abolished when it was demonstrated that cysticerci are larval stages of T. solium. Therefore, when mentioning cysticerci it should only be stated "celluosae type of T. solium cysticerci" or simply "T. solium cysticerci". Yoshino published detailed histological descriptions of the development of cysticerci, including the formation of the scolex and the size and appearance of its hooks, after he fed proglottids to pigs, released by him because he ingested cysticerci [5-8] and Rabiela demonstrated that there are intermediate forms between a cellulose and a recemose type cysticercus and that cysticerci evaginate through a pore. (Figure 4) [9, 10].
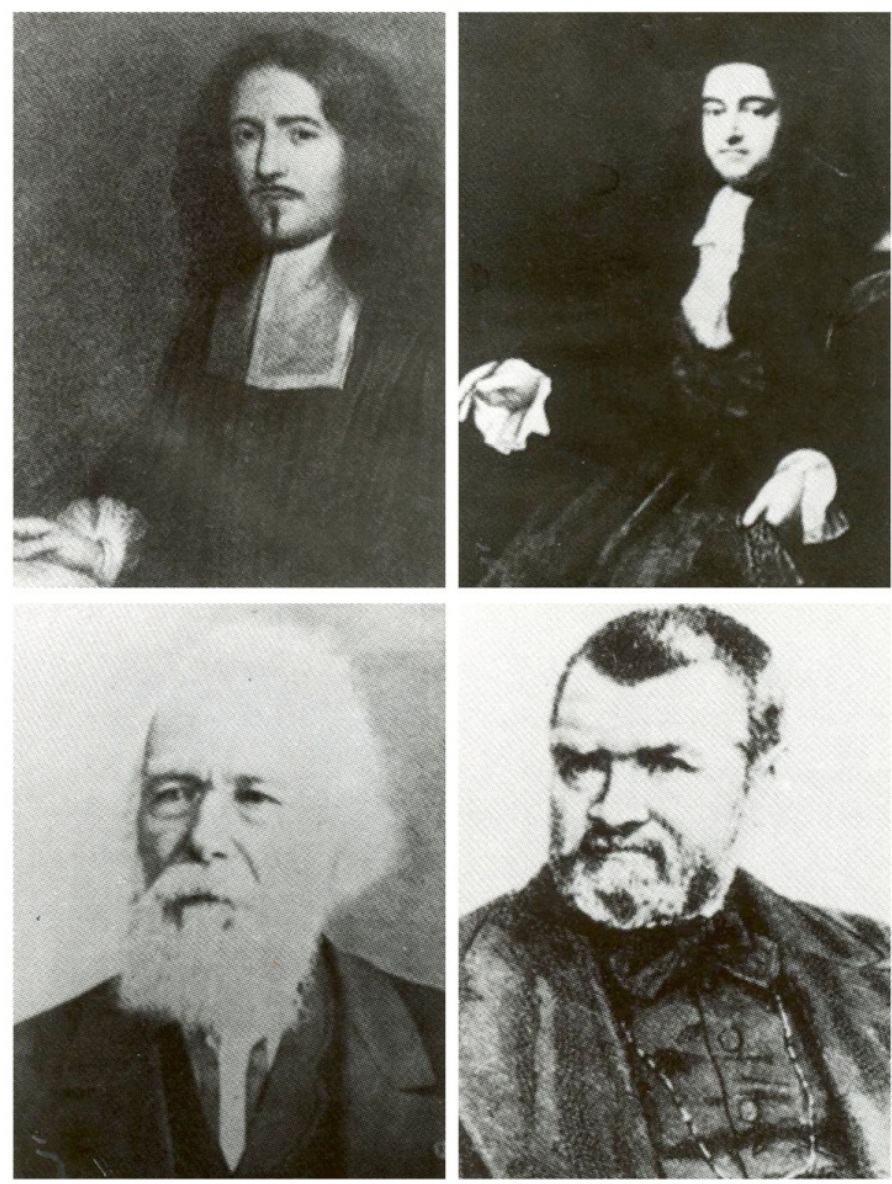

Figure 3. Photograps of M. Malpighi, E. Tyson, PJ van Beneden and F Kuchenmeister 

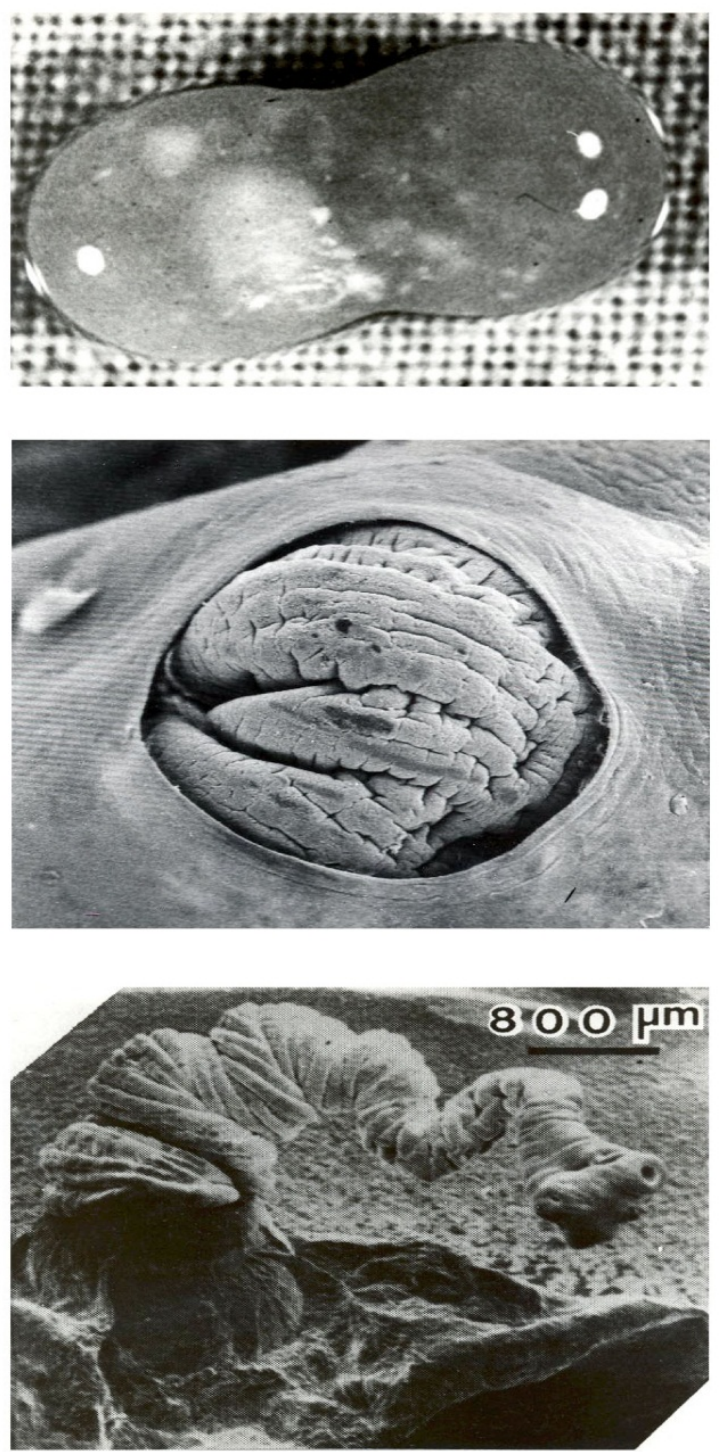

Figure 4. Micrographs of the evagination pore of a cysticercus and an evaginated cysticercus as well as a photograph of a bilobulated cysticercus; its appearance suggests the beginning of transformation from a cellulosae to a racemos type cysticercus. Kindly donated by Dr. Maria Teresa Rabiela (RIP)

The first report regarding NCC in Mexico, probably lost in the old Mexican literature, was published in 1901; the author, Dr. Ignacio Gómez-Izquierdo, described a patient from Cuba who died in a psichiatric asylum with diagnosis of alcoholism or tuberculosis. During necropsy multiple cysticerci were found. The author stated his doubts regarding the diease: "Diagnosis is almost impossible, because, with the exception of those cases in which 
cysticerci are found in superficial tissues or in the eye, symptomatology by itself does not provide enough information in order to establish its diagnosis, and, if diagnosis could have been done with precision, would prognosis stop to be fatal? Are there medical or surgical treatments to successfully fight this disease? Our answer, sadly to say, is negative" [11]. The questions posed by Dr. Gómez-Izquierdo 110 years ago have illuminated the path of knowledge and reflect major advances in the last 30 years because NCC is diagnosed and treated with high efficiency and its fatality rate has dramatically diminished $[12,13]$.

\section{Epidemiology}

Human cysticercosis was considered in the past to be less frequent than taeniosis due to the possibility of finding a tapeworm in feces, while muscle cysticerci mostly do not cause clinical signs and neurocysticercosis generally could not be identified due to its pleomorphic symtomatology $[14,15]$. Interest in NCC arouse after Dixon and Lipscomb identified soldiers that acquired NCC when they were were stated in India [16]. This study is the only one that allowed identifying the duration of the disease and of the appearance of clinical manifestations, since it became clear when soldiers acquired NCC while stationed in India. Figure 5 shows a histogram of the time when soldiers presented the first convulsive crisis and/or subcutaneous nodules; as it can be seen in around 50\% symptoms appeared two to four years after being in India, and cases were also identified as far as 30 years afterwards. MacArthur suggested that symptomatology was due to the death of parasites and suggested that the biological objetive of cysticerci, while in the tissues of the intermediate host, is to remain silent in order to be able to continue their life cycle. He also suggested that parasite death could be associated to toxin release that increases irritation [17].

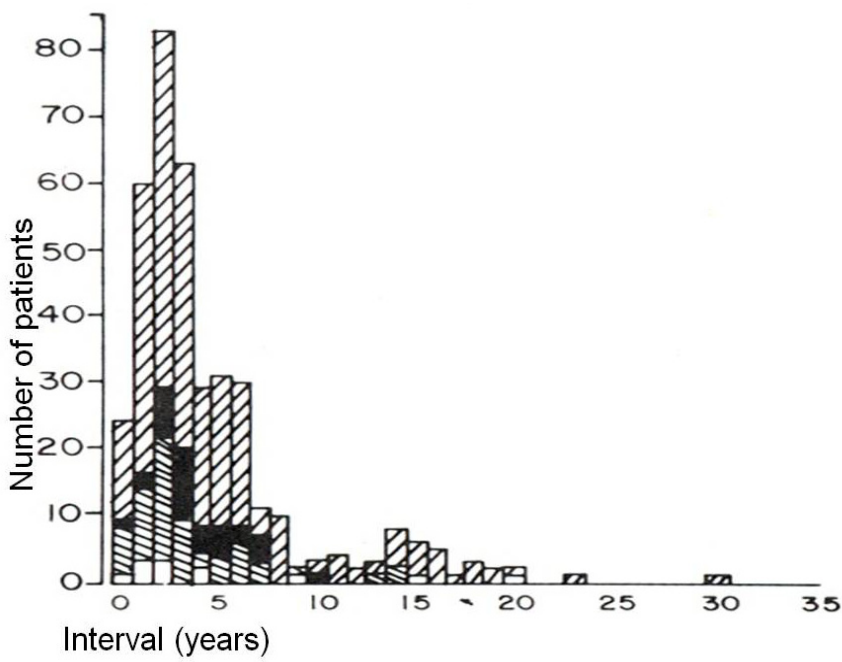

Figure 5. Histogram showing the interval in years in which signs and symptoms related to cysticercosis appearaed in 450 soldiers after they returned from being stationed in India. Convulsive crisis $(/ / /)$, subcutaneous nodules $(\backslash \backslash \backslash$ ), both (black) or other data (white), reproduced from [16]. 
Because human cysticercosis is a disease related to underdevelopment, it is present in countries that lack proper sanitary infrastructure and hygiene as well as insufficient health education $[15,18,19]$. An outstanding example is the emergence of neurocysticercosis in West New Guinea among the Ekari population, to whom the disease was unknown prior to the entrance of cysticercotic pigs as official gifts. Some $18-20 \%$ of the population acquired cysticercosis. The disease was detected by an epidemic of severe burns resulting from convulsions manifested while the people were sleeping around house fires; individuals also had subcutaneous nodules [20]. Between the 1940's and 1970's several reports of human necropsies performed in Latin America revealed the presence of cysticerci in the brain with different frequencies, so high that NCC is considered a public health problem in some countries [15,21,22]. As it can be seen in table 1, necropsies performed in Mexico reported an average of $2 \%$ of NCC. In addition, hospital-based reports provided data on the magnitude of cysticercosis in patients; the National Institute of Neurology and Neurosurgery reported a prevalence of $6 \%$ among its neurological patients [23]. This prompted the development and standardization of immunodiagnostic assays, and the detection of specific serum antibodies facilitated the shift to epidemiological information instead of that coming from autopsies, because these do not strictly represent the Mexican population since they were performed in people dying in public government hospitals, while seroepidemiological surveys are performed in open populations including both rural and urban settings [24].

\begin{tabular}{|l|l|l|}
\hline Country & Years reported & $\%$ \\
\hline Peru & $1961-1974$ & 5.9 \\
\hline Mexico & $1947-1957$ & 2.8 \\
\hline Brazil & $1960-1979$ & 2.4 \\
\hline Brazil & $1965-1970$ & 2.2 \\
\hline Mexico & $1963-1974$ & 2.2 \\
\hline Brazil & $1992-1997$ & 1.5 \\
\hline Mexico & $1963-1973$ & 1.5 \\
\hline Mexico & $1953-1970$ & 1.3 \\
\hline Peru & $1961-1974$ & 0.99 \\
\hline Colombia & $1944-1964$ & 0.78 \\
\hline Chile & $1939-1966$ & 0.70 \\
\hline Venezuela & 1967 & 0.49 \\
\hline Ecuador & $1947-1968$ & 0.47 \\
\hline Costa Rica & 1967 & 0.45 \\
\hline Colombia & $1955-1970$ & 0.40 \\
\hline El Salvador & 1961 & 0.40 \\
\hline Chile & $1947-1979$ & 0.09 \\
\hline Honduras & $1951-1966$ & 0.02 \\
\hline
\end{tabular}

Table 1. Frequency of neurocysticercosis in necropsies 
For the first seroepidemiologic studies reported in Mexico, immunoelectrophoresis was used, initially in communities in the state of Chiapas: 1610 samples obtained from 9 communities, mostly rural, were analyzed. Interestingly, in spite of the low sensitivity of immunoelectrophoresis $(50 \%)$, its high specificity $(100 \%$ because practically no echinococcosis is found in Mexico) allowed to identify a clear correlation: communities with less than 4000 inhabitants had 1-8\% seropositivity, while populations with more inhabitants (35,000 was the biggest) had $1 \%$ or less antibody frequency; indicating that the parasite was more prevalent in small, an thus less developed, towns [25]. Afterwards, using 20,000 samples from a national survey, a central area in Mexico, in which people had between 0.6 and $1 \%$ of anti-cysticercus antibodies, was identified; remarkably this geographic area, called "El Bajio", is the most important pig breeding area for national consumption of pork meat [26]. A few years later, in El Sotano, a small community in the state of Hidalgo, $6 \%$ of the 124 inhabitants had antibodies detected by ELISA, 25\% of their pigs had cysticerci that were palpated in their tongues and 3\% of the people had Taenia eggs. Ascaris, Trichuris and Toxocara eggs were found in soil samples but no Taenia eggs were identified in soil. The clustered distribution of infected pigs, tapeworm carriers and people with serologic or clinical evidence of cysticercosis suggested intra-household transmission. Furthermore, although the correlation of seropositivity and clinical history suggestive of NCC in individual residents was poor, there was an apparent spatial association between tapeworm carriers and persons with serologic or clinical histories associated to NCC [27]. This information was very interesting because it identified, for the first time ever, the main risk factor for NCC: the presence of a person infected with an adult tapeworm at home (which I consider my most important contribution to the control of NCC), instead of egg transmission through strawberries, lettuce, coriander and any other vegetable grown at floor level, eaten unpeeled, uncooked and probably unwashed, that could have been irrigated with sewage.

In a study undertaken in order to determine markers of $T$. solium transmission and risk factors in an urban community, 1000 soldiers from a military camp in Mexico City and their families were studied. Serum samples were used to detect cysticercus antigens and antibodies and fecal specimens were examined for Taenia coproantigens (CpAgs) and eggs. Antibodies were detected in $12.2 \%$ of soldiers and $5.8 \%$ and $10 \%$ of relatives of positive and negative soldiers, respectively. Antigens in serum were detected in $2.8 \%$ of the soldiers and in $4.2 \%$ of the relatives of antibody-positive soldiers. CpAgs were found in $0.5 \%$ and Taenia eggs in $0.1 \%$ of soldiers but were not found in their families. Interestingly, $12 \%$ of the family members of positive soldiers had had a history of proglottid release, compared to only $3.7 \%$ of the family members of negative soldiers. Lastly, $86 \%$ of the family members of positive soldiers had eaten in street food stores, compared to only $62.5 \%$ of those of negative soldiers. Both risk factors identified were statistically significant, indicating again, that the main risk factor was an association with the presence of a tapeworm carrier at home confirming its importance for the transmission of T. solium [28]. Therefore, a clinical history of taeniosis in a family member, defined as elimination of proglottids in feces, should be taken into account by health personnel in order to be treated in spite of being asymptomatic, and to prevent other members of the family from becoming infected. Likewise, public health authorities should control street food vendors to reduce new cases of T. solium infections by 
means of hygienic and sanitary measures. The results obtained support that the prevalence of human cysticercosis in Mexico was, as indicated by previous necropsy findings, around $2 \%$, while the prevalence of antibodies was much higher, suggesting exposure to the parasite but not current infection. In another national survey, using indirect hemaglutination, a similar antibody prevalence was found $(15 \%$ of the 11,611 homes analyzed), and $2.2 \%$ had two or more seropositive members, pointing to the presence of an intestinal tapeworm carrier [29].

Many epidemiological surveys were performed with ELISA in the 1980's, supported by direct detection of cysticerci in pigs' tongue and tapeworm eggs in human feces [27, 28, 3034] and, in the 1990's, by western blot (WB) [27, 30, 35-41] using an enriched fraction of glycoproteins as antigen source [42] allowing the demonstration of the presence of all the components of the life cycle (Tables 2 and 3), [24]). Table 3 also shows that swine cysticercosis is higher in Peru, suggesting that Peruvian pigs have easier access to human feces. Furthermore, one survey was performed in two rural communities of Mexico in order to compare the performance of both assays; 2524 individuals were studied, $7.5 \%$ were positive by $\mathrm{WB}, 2.1 \%$ by ELISA and only $3.1 \%$ in both assays [43]. Reports of predictive values indicate that for screening purposes, $\mathrm{WB}$ would be the test of choice, and for diagnosis, performing $\mathrm{WB}$ and $\mathrm{CT}$ tests would yield the best results, although with clinical data suggestive of NCC even ELISA is useful to support diagnosis [24].

\begin{tabular}{|c|c|c|c|c|c|}
\hline $\begin{array}{c}\text { Community } \\
\text { studied, state }\end{array}$ & Year & $\begin{array}{c}\text { Number of } \\
\text { samples }\end{array}$ & $\begin{array}{c}\text { \% pigs with } \\
\text { tongue } \\
\text { cysticerci }\end{array}$ & $\begin{array}{c}\text { \% people } \\
\text { with eggs in } \\
\text { feces }\end{array}$ & $\begin{array}{c}\text { \% people } \\
\text { positive in } \\
\text { ELISA }\end{array}$ \\
\hline El Sótano, Hidalgo & 1984 & 124 & 24 & 3.1 & 6 \\
\hline San Pedro Martir, DF & 1985 & 928 & 0 & 0 & 0 \\
\hline El Salado, Sinaloa & 1986 & 432 & Present & 1.2 & 12 \\
\hline Los Sauces, Guerrero & 1987 & 440 & 6.6 & 3.0 & 2.3 \\
\hline La Curva, Sinaloa & 1989 & 549 & 1.4 & 1.3 & 11 \\
\hline
\end{tabular}

Table 2. Epidemiologic studies performed with ELISA for detection of people with anti-cysticercus antibodies

When data from table 1 are compared to those of tables 2 and 3, it is evident that the prevalence of anti-cysticercus antibodies in humans $(2.3-24 \%)$ is much higher than the finding of the parasite in pathology studies (0.02-5.9\%), indicating that antibodies reflect exposure and not necessary the presence of the parasite; its serologic confirmation can be obtained by detecting cysticercal antigens. One survey used monoclonal antibodies in a capture ELISA [44,45] in 900 inhabitants of the community of Cerritos, San Luis Potosí, 1\% positive samples for antigens and $4.2 \%$ for antibodies were found, only one sample was positive in both tests. Interestingly, although antigen detection was lower, two of the three positive cases that accepted undergoing computed tomography (CT) had images compatible with cysticerci, while only two of the seven antibody positive individuals had CT images resembling cysticerci [46]. These data point to a higher correlation with the disease in open populations when parasite antigens are being searched than when antibodies are detected. 
Another field study showed and association between the presence of antigens and that of late onset epilepsy, while antibodies were associated to the presence of subcutaneous nodules; furthermore specificity and positive predictive values for the antigen capture ELISA was high with samples of epileptic people [47]. It has also been demostrated that this capture ELISA is useful to evaluate symtomaticos patients, who can benefit with immediate treatment [48]. Similar studies have been implememented in the last decade in Asia and Africa.

\begin{tabular}{|c|c|c|c|c|c|}
\hline $\begin{array}{c}\text { Community } \\
\text { studied, state }\end{array}$ & Year & $\begin{array}{c}\text { Number of } \\
\text { samples }\end{array}$ & $\begin{array}{c}\text { \% pigs with } \\
\text { tongue } \\
\text { cysticerci }\end{array}$ & $\begin{array}{c}\text { \% people } \\
\text { with eggs in } \\
\text { feces }\end{array}$ & $\begin{array}{c}\text { \% people } \\
\text { positive in } \\
\text { WB }\end{array}$ \\
\hline Xoxocotla, México & 1988 & 13227 & 4 & 0.3 & 11 \\
\hline Angahuan, México & 1988 & 3065 & 6.5 & 0.5 & 5 \\
\hline Churusapa, Perú & 1988 & 279 & 49 & 1 & 7 \\
\hline Maceda, Perú & 1988 & 421 & 43 & 1 & 8 \\
\hline Haparquilla, Perú & 1990 & 365 & 46 & ND & 13 \\
\hline Jocote, Guatemala & 1991 & 1161 & 14 & 3 & 17 \\
\hline Quesada, Guatemala & 1991 & 1204 & 4 & 1 & 10 \\
\hline Saylla, Perú & $1990-3$ & 501 & 36 & 3 & 24 \\
\hline San Pablo, Ecuador & 1992 & 2723 & ND & ND & 10 \\
\hline Tegucigalpa, Honduras & 1998 & 404 & ND & 0.6 & 16 \\
\hline Salama, Honduras & 1999 & 480 & ND & 2.5 & 17 \\
\hline Cd. de México, México & 1999 & 1000 & ND & 0.5 & 12 \\
\hline
\end{tabular}

Table 3. Epidemiologic studies performed with western blot for detection of people with anticysticercus antibodies

\section{Risk factors and intervention trials}

It has been considered for a long time in Mexico that fruits, such as strawberries, and vegetables, such as lettuce, that are eaten unpeeled and uncooked and that grow at ground level, are the main sources of Taenia eggs that cause human NCC. But in a study carried out in the counties of Irapuato in the state of Guanajuato and Zamora, Michoacan, which are important locations for the production of strawberries, no Taenia eggs were identified in large amounts of homogenized strawberries collected throughout one year but low numbers of protozoan cysts and one Ascaris egg were found [49]. This indicated that, although there was contamination with human feces, strawberries did not carry tapeworm eggs. Also, the absence of Taenia eggs in domestic flies was demonstrated in the community of Tianquizolco, where over one thousand flies were caught in homes and assessed for their role in the transmission of Taenia solium [50]. On the other hand, multiple studies have demonstrated that the prevalence of tapeworm carriers is higher among household members of NCC patients than in the rest of the population [27,51, 52]. For transmission of NCC the importance of a tapeworm carrier in the household and not of egg ingestion in strawberries or of contaminated flies changes the concept of control, since it is much easier 
and cheaper to treat tapeworm carriers than to modify sewage and irrigation in developing countries with huge territories.

A clear asociation exists between the presence of taeniosis and the severity of NCC, therefore the perception that T. solium tapeworms are silent guests causing no harm to humans is erroneous, and tapeworm carriers should be regarded as potential sources of contagion to both themselves and to those living in their close environment [53]. Just how important is the presence of a tapeworm carrier was demonstrated by the case of 4 orthodox Jewish families from New York, in which 4 neurological cases and 7 seropositive people were along two years after. Although these families did not ingest pork meat, the maid who cooked for these families was from Mexico and she had an intestinal T solium [54].

The information presented above clearly demonstrates a clustered distribution of persons with serological or clinical evidence of cysticercosis, infected pigs and tapeworm carriers, thus allowing to evaluate intervention measures: health education, self-detection of tapeworm carriers, mass treatment against human taeniosis and pigs vaccination. Regarding health education as a community-based intervention measure, a comprehensive study was undertaken in Chalcatzingo, Morelos with approximately 2000 inhabitants. An educational program was developed to identify the local knowledge of both diseases (taeniosis and cysticercosis) and of both parasites (the tapeworm and the cysticercus), in order to promote recognition of the parasites and knowledge of the transmission, and to improve hygienic behavior and sanitary conditions that foster transmission. This was performed by in-depth questionnaires developed by anthropologists. Based on the information obtained, an educational intervention was developed which included explanation of the life cycle, diseases, risk factors and control measures. For this purpose the anthropologists trained local leaders, selected among students, housewives, and teachers as well as the priest, to be in charge of promoting and providing health education, so that education remained in the community after the project ended. The effects of this educational intervention were evaluated by measuring changes in knowledge, attitudes and practices (Table 4) and prevalences of human taeniosis and swine cysticercosis before and after the campaign [56]. The prevalence in pigs at the start of the education intervention was $2.6 \%$ and $5.2 \%$ by tongue examination and western blot for antibody detection, respectively. Approximately one year after the intervention they were $0 \%$ and $1.2 \%$, respectively, and remained so for almost 4 years. (Figure 6) [57].

Apparently an economic factor facilitated the success, since people learned that by having pigs restrained in certain areas without access to human feces or garbage they would not acquire the disease and thus could be sold at a higher price. In Coapeche, Veracruz, where swine cysticercosis was ascertained by western blot, none of the 53 pigs studied had antibodies or cysticerci. Latrines were present in $91 \%$ of houses and pigs were kept in restrained areas, demonstrating that adequate basic sanitary conditions and pig breeding practices are effective and practical to control T. solium in rural communities [58]. High standards of meat inspection and proper disposal of infected pig carcasses will also aid in preventing infected pigs from entering the food chain. 


\begin{tabular}{|c|c|c|c|c|}
\hline $\begin{array}{l}\text { Effect detected by the } \\
\text { anthropologic questionnaire }\end{array}$ & \begin{tabular}{|l} 
Before \\
intervention
\end{tabular} & \begin{tabular}{|l} 
After \\
intervention
\end{tabular} & At 6 months & \begin{tabular}{|l|} 
At 42 \\
months \\
\end{tabular} \\
\hline Chalcatzingo (Health education) & $\%$ & $\%$ & $\%$ & $\%$ \\
\hline Free roming pigs & 29 & 9 & 6 & 4 \\
\hline Pigs that ingest feces & 31 & 16 & 14 & 0 \\
\hline Outdoors fecalism & 49 & 47 & 44 & 21 \\
\hline Atotonilco (Cestocidal treatment) & $\%$ & $\%$ & $\%$ & $\%$ \\
\hline Free roming pigs & 18 & 16 & 40 & 3 \\
\hline Pigs that ingest feces & 20 & 22 & 15 & 3 \\
\hline Outdoors fecalism & 50 & 45 & 45 & 39 \\
\hline Tetelilla (Both interventions) & $\%$ & $\%$ & $\%$ & $\%$ \\
\hline Free roming pigs & 48 & 32 & 17 & 14 \\
\hline Pigs that ingest feces & 40 & 38 & 30 & 17 \\
\hline Outdoors fecalism & 78 & 70 & 60 & 52 \\
\hline
\end{tabular}

Table 4. Main effects of the intervention as per the anthropologic questionnaire

Porcine cysticercosis

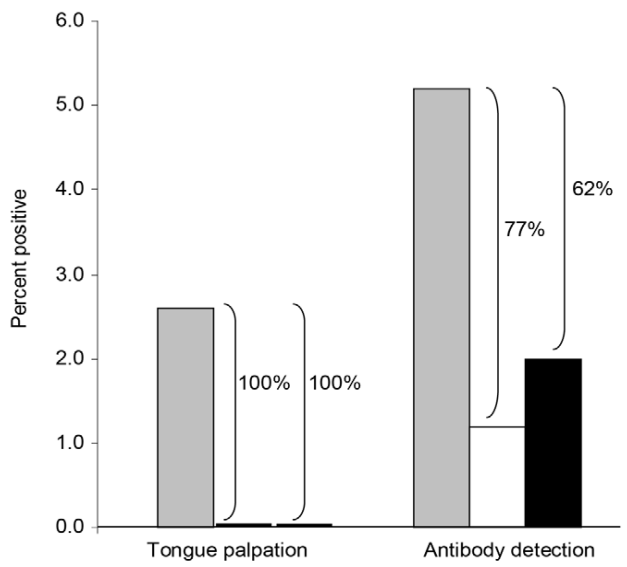

Human taeniosis

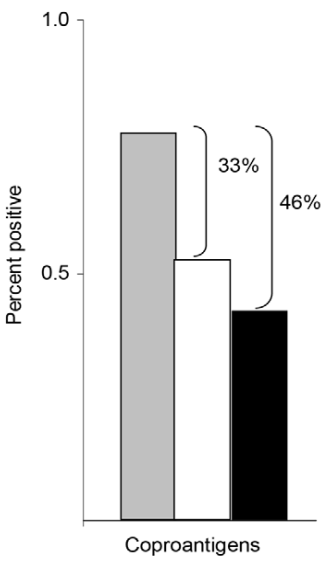

Figure 6. Effect of health education provided to the community of Chalcatzingo, Morelos, Mexico. Evaluation of porcine cysticercosis was measured by tongue palpation and serum antibodies detected by Western blot, while that of human taeniosis was measured by coproantigen detection. Assessment was performed before intervention ( $n=1,404$ for humans and 194 for pigs), 6 months later ( $n=792$ for humans and 165 for pigs), and 42 months later in 1996 ( $\mathrm{n}=605$ for humans and 334 for pigs). Reproduced from [57].

Self-identification of tapeworm carriers as a community based intervention, alternative to health education, was evaluated in the municipality of Irapuato, Guanajuato. Clinical and animal health care practitioners and schoolteachers were trained in the life cycle, risk factors 
and control measures related to infection with Taenia solium. Over 120 small glass bottles, each containing a few tapeworm segments fixed in formaldehyde and an instructional guide were distributed among all clinical practitioners (physicians and nurses) working in health centers. The guide contained 10 key points on how to ask questions about tapeworm infections. The small bottles were shown during questionnaire administration to all people that attended the clinic for any medical reason in order to determine if they had seen such parasites in their feces or their family. Information on taeniosis and cysticercosis was also provided to the general population via different media. Seven tapeworm carriers were recorded in the official epidemiology surveillance system the year previous to the study, interestingly, the year after the study, 41 tapeworm carriers (37 T. saginata; 4 T. solium) were recorded. Thus six times more tapeworm carriers were notified after the study. All four persons with $T$. solium were treated, thereby eliminating the parasite and subsequently preventing new cases of human and swine cysticercosis that might have arisen [59]. This study demonstrates that self-detection is a feasible tool for control of T. solium.

The use of mass treatment with praziquantel to eliminate tapeworms from human carriers as a community-based intervention measure was evaluated in two studies. In a small community (559 inhabitants) in La Curva, Sinaloa, over $70 \%$ of the population over 5 years of age was treated with a $10 \mathrm{mg} / \mathrm{kg}$ dose. One year later, no infections with Taenia sp. eggs were found and no pigs with cysticercosis were detected. Seropositivity using ELISA was $11 \%$ before treatment and $7 \%$ afterwards, in the 30-39 year age group, antibody detection decreased from $30 \%$ to $7 \%$ suggesting that elimination of tapeworms reduces the possibility of contact with infective eggs. Interestingly, in the geographic section of the community where 3 of the 4 tapeworm carriers were found and treated, seropositivity was reduced from $19 \%$ to $2 \%$, indicating that serum antibodies to Taenia antigens are short-lived and diminish, as contact with the parasite is lost [34]. In the second study performed in Atotonilco (3007 inhabitants), $87 \%$ of the community received a single dose of $5 \mathrm{mg} / \mathrm{kg}$ following a recommendation from WHO [60]. The prevalence of taeniosis was reduced by $53 \%$ after 6 months and by $56 \%$ after 42 months, as measured by CpAg ELISA or egg detection; late onset general seizures decreased by $70 \%$. Anti-cysticercus antibodies in the human population were reduced by $75 \%$ after 42 months and antibodies in pigs also showed a significant reduction (55\%) after 6 months [61]. In conclusion, the impact of mass chemotherapy against taeniosis to control cysticercosis in the short and long term was successfully demonstrated. Experience with praziquantel however suggested that it should not be given at doses lower than $10 \mathrm{mg} / \mathrm{kg}$. This population-based cestocidal treatment eliminated tapeworm carriers but generated symptomatology in a previously asymptomatic neurological case [62]. This observation highlights the importance of weighing targeted treatment, instead of mass drug administration, which can be used since potential tapeworm carriers are identified by direct questioning or by detection of parasite antigens or eggs, as well as by association with late onset epilepsy.

Another alternative for the control of cysticercosis is vaccination, especially because pigs are the only intermediate hosts that participate in the maintenance of the parasite in the environment. Based on the high protection obtained with recombinant antigens identified in T. ovis and T. saginata $[63,64]$, recombinant vaccines against $T$. solium were elaborated. For 
this cDNA from a genomic library from a T. solium tapeworm was prepared and with probes from $T$. ovis $18 \mathrm{k}$ and $45 \mathrm{k}$ antigens, the homologue recombinant DNAs were identified and cloned in E. coli. The oncosphere recombinant antigens were purified and used to vaccinate pigs in two independent trials performed in different institutions under controlled conditions. The first one was in 2000 and the second one in 2002. Each pig received 200ug of recombinant antigen TSOL18 or TSOL45 or the carrier, Glutathione S Transferase (GST) as a control group, with $1 \mathrm{mg}$ Quil A as adjuvant, intramuscularly each 15 days, in two occasions in the first experiment and thrice in the second one. For challenge, gravid proglottids were separated from a tapeworm recovered from a carrier. Proglottids were minced; eggs were obtained by sieving, washed, counted and used to challenge pigs 3 weeks after the 2nd or 3rd immunization, respectively. Each pig received orally 40,000 eggs in the first experiment, and 9,000 in the second one. Necropsies were performed 3-4 months after challenge infection, carcass musculature was sliced with hand-held knives or scalpels, and the number and viability of cysticerci were determined. Table 5 shows the results of both vaccination trials. Protection was calculated as the percent reduction in the mean number of cysticerci in each group in comparison with the mean number of cysticerci in the control group; as it can be seen, in both experiments TSOL18 give practically full protection. TSOL45 gave a high value of protection in the second experiment but no protection was detected in the first one [65].

\begin{tabular}{|l|l|c|c|}
\hline $\begin{array}{l}\text { Number of cysticerci in experiment } 1 \\
\text { (infected with } 40,000 \text { eggs per pig) }\end{array}$ & $X$ & $\begin{array}{c}\text { Protection } \\
(\%)\end{array}$ \\
\hline GST & $167,206,234,262,415$ & 257 & \\
\hline TSOL18 & $0,0,0,0,0$ & 0 & 100 \\
\hline $\begin{array}{l}\text { Number of cysticerci in experiment } 2 \\
\text { (infected with 9,000 eggs per pig) }\end{array}$ & $X$ & $\begin{array}{c}\text { Protection } \\
(\%)\end{array}$ \\
\hline GST or PBS & $\begin{array}{l}6,10,11,13,17,26,28,40, \\
59,64,100,127\end{array}$ & 42 & \\
\hline TSOL18 & $0,0,0,0,1$ & 0.2 & 99.5 \\
\hline
\end{tabular}

Table 5. Number of cysticerci found in individual pigs

The humoral immune response of all pigs was evaluated against the cysticercal enriched glycoprotein antigen used for the diagnosis of human cysticercosis [42] specific diagnostic bands were obtained in all control pigs but not in immunized pigs that did not developed cysticerci. The immune response was also evaluated against the vaccinating antigen by ELISA; specific, complement-fixing antibodies against the recombinant antigens increased after challenge and thereafter decreased; Furthermore, these and oncosphere antigens from other taeniid cestodes, contain a protein sequence motif suggesting a tertiary structure similar to the fibronectin type III domain [66]. Vaccination results show that pigs became protected from acquiring cysticercosis in experimental conditions, therefore they were evaluated in field trials in Peru [67] and Cameroon [68]; similar high levels of protection were obtained. 


\section{Conclusion}

Many epidemiological studies have shown a correlation between human cysticercosis, taeniosis and epilepsy and between seropositive people, infected pigs and disposal of feces and have identified community, behavioural and environmental practices that must be modified to prevent continued transmission of cysticercosis and taeniosis.

Table 6 summarizes those that the author considers the most relevant. Most importantly, these studies have shown that the main risk factor is the presence of a Taenia carrier in the immediate environment. A proposal to declare neurocysticercosis an international reportable disease has been published [69].

This proposal, if taken in account, could be helpful in the control of cysticercosis, since, if cases of cysticercosis and of taeniosis are reported in all countries, it will provide accurate quantification of the incidence and prevalence of neurocysticercosis at regional level, thus permitting the rational use of resources in eradication campaigns. Although NCC is endemic in several countries of Latin America, Sub-Saharan Africa and Asia [69], due to migration there are many patients with NCC that attend hospitals in several cities of the USA and, even more important is the fact that tapeworm carriers have been identified in USA and even in Muslim countries, therefore now cysticercosis is considered an emerging infectious disease in USA and in some of its states it is now a reportable disease. [19,70,71]. It should be noted that approximately 200 million people cross the Mexico-USA border each year, multiplying the opportunities of acquiring and transporting adult T. solium [72].

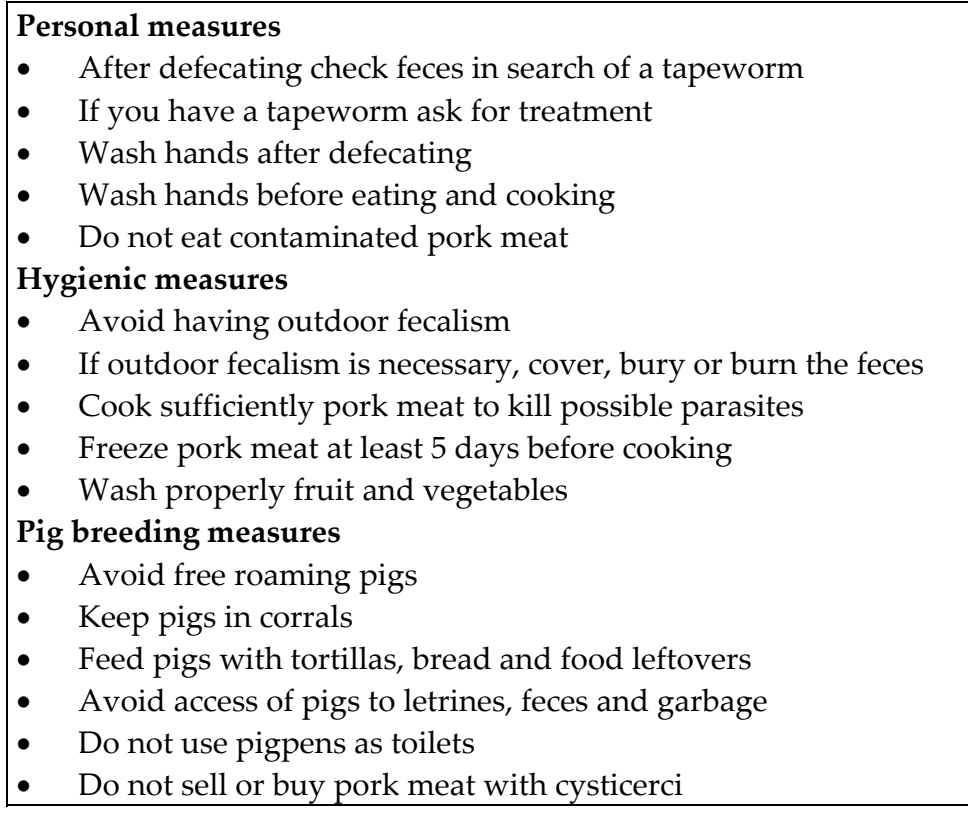

Table 6. Preventive measures against cysticercosis 
The efforts and advancements described above, and others, drove Mexico onto a new stage regarding NCC: it is not anymore a public health problem. This parasitic disease was recognized as a public health problem when necropsy cases, published between 1947 and 1970, reported high frequencies of NCC. A recent publication [57] indicates that this disease has been controlled; the idea is supported by the dramatic decrease in the frequency of human NCC and human taeniosis obtained from the National Information System for Epidemiological Surveillance of the Ministry of Health in Mexico. The decrease was probably due to three reasons: 1 ) the abundant literature published by the Mexican scientific and medical communities working on cysticercosis; 2) the establishment of a National Program for the Control of Taenia solium since 1994; 3) the living conditions in Mexico have improved greatly in social, economy and health sectors.

\section{Author details}

Ana Flisser

Department of Microbiology and Parasitology, Faculty of Medicine, National Autonomous University of Mexico (UNAM), Mexico DF

\section{Acknowledgement}

This chapter is dedicated to all the students and collaborators that I have had along 40 years in cysticercosis research. Gustavo Barradas, Unidad de Informatica y Telecomunicaciones, Facultad de Medicina, UNAM, provided technical support in the preparation of the manuscript.

\section{References}

[1] Flisser A. Neurocysticercosis in Mexico. Parasitology Today 1988;4:131-137.

[2] Bruschi F, Masetti M, Locci MT, Ciranni R, Fornaciari G. Cysticercosis in an Egyptian Mummy of the Late Ptolemaic Period. American Journal of Tropical Medicine and Hygiene 2006;74:598-599.

[3] Athenian Society. Aristophanes. The Knights. http://ebooks.adelaide.edu.au/a/ aristophanes/knights/ The University of Adelaide Library, University of Adelaide, South Australia. The text appears to be derived from the edition published in 1912 by an anonymous translator (accessed 8 September 2012)

[4] Grove DL. A history oh human helminthology. CABI Intl Oxon UK1990. 355-383.

[5] Yoshino K. Studies on the post-embryonal development of Taenia solium. Part I. On the hatching of the eggs of Taenia solium. Journal of the Medical Association of Formosa 1933;32:139-141

[6] Yoshino K. Studies on the post-embryonal development of Taenia solium. Part II. On the migratory course of the oncosphere of Taenia solium within the intermediate host. Journal of the Medical Association of Formosa 1933;32:155-158 
[7] Yoshino K. Studies on the post-embryonal development of Taenia solium. Part III. On the development of cysticercus cellulosae within the definitive intermediate host. Journal of the Medical Association of Formosa 1933;32:166-169.

[8] Yoshino K. On the evacuation of eggs from detached gravid proglottids of Taenia solium and on the structure of its eggs. Taiwan Igakkai Zasshi 1934:33:47-58.

[9] Rabiela MT, Ornelas Y, García-Allan C, Rodríguez del Rosal E, Flisser A. Evagination of Taenia solium cysticerci: a histologic and electron microscopy study. Archives of Medical Research 2000;31:605-607.

[10] Rabiela MT, Rivas A, Flisser A. Morphological types of Taenia solium cysticerci. Parasitology Today1989;5:357-359.

[11] Gómez-Izquierdo I. Locura por cisticercos del cerebro. Revista Médica 1901;13:205-207.

[12] Del Brutto OH, Rajshekhar V, White Jr, AC, Tsang VCW, Nash TE, Takayanagui OM, Schantz PM, Evans CAW, Flisser A, Correa D, Botero D, Allan JC, Sarti E, Gonzalez AE, Gilman RH, Garcia HH. Proposed diagnostic criteria for neurocysticercosis. Neurology 2001;57:177-183.

[13] Garcia HH, Evans CAW, Nash TE, Takayanagui OM, White AC, Botero D, Rajshekhar V, Tsang VCW, Schantz PM, Allan JC, Flisser A, Correa D, Sarti E, Friedland JS, Martinez SM, Gonzalez AE, Gilman RH, Del Brutto OH. Current consensus guidelines or treatment of neurocysticercosis. Clinical and Microbiological Reviews 2002;15:747756.

[14] Del Brutto OH. Neurocysticercosis: A Review. Scientific World Journal 2012, doi:10.1100/2012/159821

http://www.ncbi.nlm.nih.gov/pmc/articles/PMC3261519/pdf/TSWJ2012-159821.pdf accessed 8 September 2012)

[15] WHO/FAO/OIE Guidelines for the surveillance, prevention and control of aeniosis/cysticercosis. Murrell KD (ed) 2005, 139pp

[16] Dixon HBF, Lipscomb FM. Cysticercosis: an analysis and follow up of 450 cases. Privy Council for Medical Research Special Report1961;229:1-58.

[17] MacArthur WP. Cysticercosis of the brain. British Medical Journal ii 1935;1229

[18] Flisser A, Rodríguez-Canul R, Willingham III AL. Control of the taeniosis/cysticercosis complex: future developments. Veterinary Parasitology 2006;139:283-292

[19] Schantz PM, Wilkins PP, Tsang VCW. Immigrants, imagings and immunoblots: the emergence of neurocysticercosis as a significant public health problem. In: Scheld MW, Craig WA, Hughes JM. (eds) Vol 2. ASM Press, Washington DC. 1998, p213-242

[20] Wandra T, Subahar R, Simanjuntak GM, Margono SS, Suroso T, Okamoto M, Nakao M, Sako Y, Nakaya K, Schantz PM, Ito A.Resurgence of cases of epileptic seizures and burns associated with cysticercosis in Assologaima, Jayawijaya, Irian Jaya, Indonesia, 1991-95. Transactions of the Royal Society for Tropical Medicine and Hygiene 2000;94:46-50.

[21] Schenone H, Villaroel F, Rojas A, Ramírez R. (1982). Epidemiology of human cysticercosis in Latin America. In: A. Flisser A. Willms K, Laclette JP, Larralde C, Ridaura C, Beltrán F (eds). Cysticercosis. Present State of Knowledge and Perspectives. SBN 0-12-260740-6. Academic Press, New York, pp. 25-38. 
[22] Flisser A. Epidemiological studies of taeniosis and cysticercosis in Latin America. In: Cestode Zoonoses: Echinococcosis and cysticercosis, an emergent and global problem. Craig P, Pawlowski Z, (eds). IOS Press, NATO Science Series. Vol 341. Amsterdam. 2002 p.3-11.

[23] Velasco-Suarez M, Bravo-Becherelle MA, Quirasco F. Human cysticercosis: medicalsocial implications and economic impact. In: A. Flisser A. Willms K, Laclette JP, Larralde C, Ridaura C, Beltrán F (eds). Cysticercosis. Present State of Knowledge and Perspectives. ISBN 0-12-260740-6. Academic Press, New York, pp. 47-51.

[24] Flisser A, Gyorkos T. Contribution of immunodiagnostic tests to epidemiological /intervention studies of cysticercosis/taeniosis in Mexico. Parasite mmunology 2007;29:637-649.

[25] Flisser A, Bulnes I, Díaz ML, Luna R, Woodhouse E, Beltrán F, Ortega M, Larralde C. Estudio seroepidemiológico de la cisticercosis humana en poblaciones predominantemente indígenas y rurales del estado de Chiapas. Archivos de nvestigación Médica (México) 1976;7:107-113.

[26] Woodhouse, E., Flisser A. and Larralde, C. Seroepidemiology of human cysticercosis in México. In: A. Flisser A. Willms K, Laclette JP, Larralde C, Ridaura C, Beltrán F (eds). Cysticercosis. Present State of Knowledge and Perspectives. ISBN 0-12-260740-6. Academic Press, New York, pp. 11-24.

[27] Sarti E, Schantz PM, Lara-Aguilera R, Gómez H, Flisser A. Taenia solium Taeniasis and Cysticercosis in a Mexican Village. Tropical Medicine and Parasitology 1988;39:194-198.

[28] García-García ML, Torres M, Correa D, Flisser A, Sosa-Lechuga A, Velasco O, MesaLucas A, Plancarte A, Avila G, Tapia R, Aguilar L, Mandujano A, Alcántara I, Morales Z, Salcedo A, Mañon ML, Valdespino-Gómez JL. Prevalence and risk of cysticercosis and taeniasis in a urban population of soldiers and their relatives. American Journal of Tropical Medicine and Hygiene 1999;61:386-389.

[29] Larralde C, Padilla A, Hernández M, Govezensky T, Sciutto E, Gutiérrez G, TapiaConyer R, Salvatierra B, Sepúlveda J. Seroepidemiology of cysticercosis in Mexico. Salud Pública (México) 1992;34:197-210.

[30] Sarti E, Schantz PM, Plancarte A, Wilson M, Gutiérrez IO, López AS, Roberts J, Flisser A. Prevalence and Risk Factors for Taenia solium Taeniasis and Cysticercosis in Humans and Pigs in a Village in Morelos, México. American Journal of Tropical Medicine and Hygiene 1992;46:677-683.

[31] Sarti E, Schantz PM, Plancarte A, Wilson M, Gutiérrez IO, Aguilera J, Roberts J, Flisser A. Epidemiological Investigation of Taenia solium Taeniasis and Cysticercosis in a Rural Village of Michoacan State, México. Transactions of the Royal Society of Tropical Medicine and Hygiene 1994;88:49-52.

[32] Keilbach NM, de Aluja AS, Sarti E. A Programme to Control Taeniasis-Cysticercosis (T. solium): Experiences in a Mexican Village. Acta Leidensia 1989;57:181-189.

[33] Díaz-Camacho S, Candil A, Uribe M, Willms K. Serology as an Indicator of Taenia solium Tapeworm Infection in a Rural Community in México. Transactions of the Royal Society of Tropical Medicine and Hygiene 1990;84:563-566. 
[34] Díaz-Camacho S, Candil A, Suate V, Zazueta ML, Felix-Medina M, Lozano R, Willms K. Epidemiological Study and Control of Taenia solium Infections with Praziquantel in a Rural Village of México. American Journal of Tropical Medicine and Hygiene 1991;45:522-531.

[35] Cruz ME, Cruz I, Schantz PM, Dumas M. Headache and Cysticercosis in Ecuador, South America. Headache Journal 1995;35:93-97

[36] Garcia HH. Epidemiology of Taenia solium infection in Perú. In: IX International Congress of Parasitology, ICOPA IX, Monduzzi Editore SpA, Bologna, Italy, 1998, pp. 383-391.

[37] García-Noval J, Allan JC, Fletes C, Moreno E, De Mata F, Torres-Álvarez R, Soto de Alfaro H, Yurrita P, Higueras-Morales H, Mencos F, Craig PS. Epidemiology of Taenia solium Taeniasis and Cysticercosis in Two Rural Guatemalan Communities. American ournal of Tropical Medicine and Hygiene 1996;55:282-289.

[38] Garcia HH, Araoz R, Gilman RH, Valdez J, González AE, Gavidia C, Bravo ML, Tsang VCW, the Cysticercosis Working Group in Perú. Increased Prevalence of Cysticercosis and Taeniasis Among Professional Fried Pork Vendors and the General Population of a Village in the Perúvian Highlands. American Journal of Tropical Medicine and Hygiene 1998;59:902-905.

[39] Sánchez AL, Medina MT, Ljungstrom I. Prevalence of taeniasis and cysticercosis in a population of urban residence in Honduras. Acta Tropica 1998;69:141-149.

[40] Sánchez AL, Lindback J, Schantz PM, Sone M, Sakai H, Medina MT, Ljungstrom I. A population-based, case-control study of Taenia solium taeniosis and cysticercosis. Annals of Tropical Medicine and Parasitology 1999;93:247-258.

[41] Rodríguez-Canul R, Fraser A, Allan JC, Domínguez-Alpizar JL, Arfaez-Rodríguez F, Craig PS. Epidemiological Study of Taenia solium Taeniasis/Cysticercosis in a Rural Village in Yucatan State, México. Annals of Tropical Medicine and Parasitology 1999;93:57-67.

[42] Tsang VCW, Brand AJ, Boyer AE. An Enzyme-Linked Immunoelectrotransfer Blot Assay by Glycoprotein Antigens for Diagnosing Human Cysticercosis (Taenia solium). ournal of Infectious Diseases 1989;159:50-59.

[43] Schantz, P.M., Sarti, E., Plancarte, A., Wilson, M., Criales, J.L., Roberts, J. and Flisser, A. Community-based epidemiological investigations of cysticercosis due to Taenia solium: comparison of serological screening test and clinical findings in two populations in Mexico. Clinical Infectious Diseases 1994;18:879-885.

[44] Correa D, Sandoval M, Harrison LJS, Parkhouse ME, Plancarte A, Meza A, Flisser A. Human Neurocisticercosis: Comparison of Enzyme Immunoassay Capture Techniques Based on Monoclonal and Polyclonal Antibodies for the Detection of Parasite Products n Cerebrospinal Fluid. Transactions of the Royal Society of Tropical Medicine and Hygiene 1989;83:814-816.

[45] Garcia HH, Harrison LJS, Parkhouse RME, Montenegro T, Martínez SM, Tsang VCW, Gilman RH, The Cysticercosis Working Group in Peru. A Specific Antigen-Detection ELISA for the Diagnosis of Human Neurocisticercosis. Transactions of the Royal Society of Tropical Medicine and Hygiene 1998;92:411-414 
[46] Aranda-Alvarez JG, Tapia-Romero R, Celis-Quintal G, Grijalva-Otero IE, Correa D. Human Cysticercosis: Risk Factors Associated with Circulating Serum Antigens in an Open Community of San Luis Potosi, México. Annals of Tropical Medicine and Parasitology 1995;89:689-692.

[47] Correa D, Sarti E, Tapia-Romero R, Rico R, Alcántara-Anguiano I, Salgado A, Valdez L, Flisser A. Antigens and Antibodies in Sera from Human Cases of Epilepsy or Taeniasis rom an Area of México where Taenia solium Cysticercosis is Endemic. Annals of Tropical Medicine and Parasitology 1999;93:69-74

[48] Fleury A, Hernández M, Fragoso G, Parkhouse RME, Harrison LJS, Sciutto E.. Detection of secreted cysticercal antigen: a useful tool in the diagnosis of inflammatory neurocysticercosis. Transactions of the Royal Society of Tropical Medicine and Hygiene 2003;97:542-546.

[49] Spindola-Felix N, Rojas-Wastavino G, Haro-Arteaga I, Cabrera-Bravo M, SalazarSchettino PM. Parasite search in strawberries from Irapuato, Guanajuato and Zamora, Michoacan Mexico). Erchives of Medical Research 1996;27:229-231.

[50] Martinez-Maya JJ, de Aluja A, Gemmell M. Failure to incriminate domestic flies (Diptera: Muscidae) as mechanical vectors of Taenia eggs (Cyclophillidea: Taeniidae) in rural Mexico. ournal of Medical Entomology 2000;37:489-491.

[51] Flisser A. Risk factors and control measures for taeniosis/cysticercosis. In: Cestode Zoonoses: Echinococcosis and cysticercosis, an emergent and global problem. Craig P, Pawlowski Z, (eds). IOS Press, NATO Science Series. Vol 341. Amsterdam. 2002, p.335342.

[52] Lescano AG, Garcia HH, Gilman RH, Guezala MC, Tsang VC, Gavidia CM, Rodriguez S, Moulton LH, Green JA, Gonzalez AE; Cysticercosis Working Group in Peru. Swine cysticercosis hotspots surrounding Taenia solium tapeworm carriers. American Journal of Tropical Medicine and Hygiene 2007;76:376-383

[53] Flisser A. Relación huésped-parásito en la cisticercosis humana y porcina (Trabajo de ngreso). Gaceta Médica de México 1987;123:157-164.

[54] Gilman RH, Del Brutto OH, García HH, Martínez M, the Cysticercosis Working Group n Perú. Prevalence of taeniosis among patients with neurocysticercosis is related to severity of infection. Neurology 2000;55:1062

[55] Schantz PM, Moore AC, Muñoz JL, Hartman BJ, Schaefer JA, Aron AM, Persaud D, Sarti E, Wilson M, Flisser A. Neurocysticercosis in an orthodox Jewish community in New York City, New England Journal of Medicine 1992;327:692-695.

[56] Sarti E, Flisser A, Schantz P, Gleizer M, Loya M, Plancarte A, Avila G, Allan J, Craig P, Bronfman M, Wijeyaratne P. Development and evaluation of a health education ntervention against Taenia solium in a rural community in Mexico. American Journal of Tropical Medicine and Hygiene 1997;56:127-132.

[57] Flisser A, Correa D. Neurocysticercosis may no longer be a public health problem in Mexico. PLoS Neglected Tropical Diseases 2010;4(12):e831.doi:10.1371

[58] Vázquez-Flores S, Ballesteros-Rodea G, Flisser A, Schantz P. Hygiene and restraint of pigs associated with absence of Taenia solium cysticercosis in a rural community of Mexico. Salud Pública de México 2001;43:574-576. 
[59] Flisser A, Vázquez-Mendoza A, Martínez-Ocaña J, Gómez-Colín E, Sánchez Leyva R, Medina-Santillán R. Evaluation of a self-detection tool for tapeworm carriers for use in public health. American Journal of Tropical Medicine and Hygiene 2005;72:510-512.

[60] Pawlowski Z. Efficacy of low doses of praziquantel in taeniosis. Acta Tropica 1991;48:83-88.

[61] Sarti E, Schantz PM, Avila G, Ambrosio J, Medina-Santillán R, Flisser A. Mass Treatment Against Human Taeniasis for the Control of Cysticercosis: a PopulationBased Intervention Study. Transactions of the Royal Society of Tropical Medicine and Hygiene 2000,94:85-89.

[62] Flisser, A., Madrazo, I., Puente, A., Schantz, P.M., Allan, J., Craig, P.S. and Sarti, E. 1993. Neurological symptoms in occult neurocysticercosis after single taeniacidal dose of praziquantel. Lancet. 342:748 (Letter).

[63] Gauci, C.G.P., Flisser, A. \& Lightowlers, M.W. 1998. Taenia solium oncosphere protein homologous to host-protective Taenia ovis and Taenia saginata $18 \mathrm{kDa}$ antigens. International ournal for Parasitology 28: 757-760.

[64] Plancarte A, Flisser A, Gauci Ch, Lightowelers MW. Vaccination against Taenia solium cysticercosis in pigs using native and recombinant oncosphere antigens. International ournal of Parasitology 1999;29:643-647.

[65] Flisser A, Gauci CG, Martinez-Ocaña J, Zoli A, Garza-Rodriguez A, Dominguez-Alpizar JL, Maravilla P, Rodriguez-Canul R, Avila G, Aguilar-Vega L, Kyngdon C, Geerts S, Lightowlers MW. Protection against porcine cysticercosis induced by vaccination with recombinant oncosphere antigens. Infection and Immunity 2004;72:5292-5297

[66] Kyngdon CT, Gauci CG, Gonzalez AE, Flisser A, Zoli A, Read AJ, Martínez Ocaña J, Strugnell RA, Lightowlers MW. Antibody responses and epitope specificities to the Taenia solium cysticercosis vaccines TSOL18 and TSOL45-1A. Parasite Immunology 2006;28:191-199.

[67] Gonzalez AE, Gauci CG, Barber D, Gilman RH, Tsang VC, Garcia HH, Verastegui M, Lightowlers MW. Vaccination of pigs to control human neurocysticercosis. American ournal of Tropical Medicine and Hygiene 2005;72:837-839.

[68] Assana E, Kyngdon CT, Gauci CG, Geerts S, Dorny P, De Deken R, Anderson GA, Zoli AP, Lightowlers MW. Elimination of Taenia solium transmission to pigs in a field trial of the TSOL18 vaccine in Cameroon. International Journa of Parasitology 2010;40:515-519.

[69] Roman G, Sotelo J, del Bruto O, Flisser A, Dumas M, Wadia N, Botero D, Cruz M, Garcia H, de Bittencourt PRM, Trelles L, Arraigada C, Lorenzana P, Nash TE, SpinaFranca A. A Proposal to Declare Neurocysticercosis an International Reportable Disease. Bulletin World Health Organization. 2000;78:399-406.

[70] Aijaz F, Ahmed A. Cysticercosis in a Muslim woman. Journal of the Pakistan Medical Association 1993;43:23-24

[71] Townes JM, Hoffmann CJ, Kohn MA. Neurocysticercosis in Oregon, 1995-2000. Emerging Infectious Diseases 2004;10:508-510. 
276 Novel Aspects on Cysticercosis and Neurocysticercosis

[72] Flisser A, Viniegra AE, Aguilar-Vega L, Garza-Rodriguez A, Maravilla P, Avila G. Portrait of human tapeworms. Journal of Parasitology 2004;90:914-916. 